\title{
CARACTERIZAÇÃO PATOGÊNICA DE ISOLADOS DO GÊNERO CYLINDROCLADIUM PATOGÊNICOS A EUCALIPTO
}

\author{
C.C. Aparecido ${ }^{1}$, E.C. Rosa ${ }^{2}$, D. Finatti ${ }^{3}$ \\ Instituto Biológico, Centro de Pesquisa e Desenvolvimento de Sanidade Vegetal, Av. Cons. Rodrigues Alves, \\ 1252, CEP 04014-002, São Paulo, SP, Brasil. E-mail: christianeceriani@biologico.sp.gov.br ${ }^{1}$ Pesquisador \\ Científico. ${ }^{2}$ Agente de Apoio à Pesquisa Científica e Tecnológica. ${ }^{3}$ Bosista CNPq/PIBIC/IB.
}

\section{RESUMO}

A utilização de espécies florestais para produção de madeira, papel e celulose é muito importante no Brasil. Dentre os gêneros botânicos utilizados destacam-se o Pinus e o Eucalyptus. Porém, com a intensificação dos cultivos, inúmeros patógenos têm passado a parasitar as plantas, principalmente durante os estágios iniciais de desenvolvimento. Fungos do gênero Cylindrocladium têm se destacado como patógenos de Pinus e Eucalyptus, levando a problemas consideráveis em regiões tropicais e subtropicais, devido às condições ambientais favorecerem o desenvolvimento do patógeno, que pode causar morte das plantas mais jovens e, no caso de Eucalyptus, também a ocorrência de manchas foliares. Observa-se, portanto, a necessidade de estudos relacionados ao gênero Cylindrocladium, patógeno que ganha importância devido à ampliação dos prejuízos econômicos que vem causando, como resultado da diversidade de hospedeiros que pode infectar. Com o objetivo de avaliar o comportamento patogênico de isolados do gênero Cylindrocladium, 14 (quatorze) culturas foram inoculadas em plantas de eucalipto. Sendo observados sintomas da doença, foi realizado re-isolamento e cultivo em meio Czapeck para identificar a existência de diferenças fisiológicas. Pôde-se constatar que existem diferenças patogênicas e fisiológicas entre os isolados. No que se refere às diferenças patogênicas, puderam ser observadas devido aos diferentes isolados produzirem diferentes tipos de lesão frente aos diferentes órgãos do mesmo hospedeiro. Quanto às diferenças fisiológicas, puderam ser constatadas pela formação de três grupos: Grupo 1-Micélio rasteiro (plano) com coloração variando de castanho-rosado pálido a castanho avermelhado intenso; Grupo 2-Micélio aéreo, com aspecto cotonoso e coloração variando de branco a palidamente róseo; Grupo 3-Micélio aéreo, com aspecto semi-cotonoso e periferia branca e centro castanho claro. Todas estas diferenças, provavelmente, sejam devidas à constituição genética distinta existente entre os isolados.

PALAVRAS-CHAVE: Calonecria, caracteres morfológicos, fisiologia. 


\section{ABSTRACT}

\section{PATHOGENIC CHARACTERIZATION OF ISOLATES OF THE GENUS CYLINDROCLADIUM PATHOGENIC TO EUCALYPTUS}

The use of forest species for the wood production, paper and cellulose is very important in Brazil. Among the botanical genera used, Pinus and Eucalyptus stand out. However, with the intensification of crops, numerous pathogens have started to parasitize plants, especially during the early stages of development. Fungi of the genus Cylindrocladium have stood out as pathogens of Pinus and Eucalyptus, leading to considerable problems in tropical and subtropical regions, due environmental conditions favoring the pathogen development, which can cause death of younger plants and, in the case of Eucalyptus, also the occurrence of leaf spots. Therefore, it is need for studies related to the genus Cylindrocladium, a pathogen that gains importance due to the expansion of the economic losses it has been causing, as a result of the diversity of hosts that it can infect. In order to evaluate the pathogenic behavior of isolates of the genus Cylindrocladium, 14 (fourteen) cultures were inoculated in eucalyptus plants. The disease symptoms were observed, re-isolation and cultivation was performed in Czapeck medium to identify the existence of physiological differences. It was found that there are pathogenic and physiological differences between the isolates. With regard to pathogenic differences, they could be observed because the different isolates produce different types of lesions in front of the different organs of the same host. As for the physiological differences, they could be seen by the formation of three groups: Group 1- flat mycelium with color ranging from pale pinkish brown to intense reddish brown; Group 2 - Aerial mycelium, with aspect shaggy like cotton and color ranging from white to pale pink; Group 3 - Aerial mycelium, with semi-cottony appearance and white periphery and light brown center. All of these differences are probably due to the distinct genetic makeup existing between the isolates

KEY WORDS: Calonectria, morphologic behaviors, physiology. 


\section{INTRODUÇÃO}

A utilização de espécies florestais para produção de madeira, papel e celulose é muito importante no Brasil. Dentre os gêneros botânicos utilizados destacamse o Pinus e o Eucalyptus. Porém, com a intensificação dos cultivos, inúmeros patógenos têm passado a parasitar as plantas, principalmente durante os estágios iniciais de desenvolvimento. Fungos do gênero Cylindrocladium têm se destacado como patógenos de Pinus e Eucalyptus, levando a problemas consideráveis em regiões tropicais e subtropicais, devido às condições ambientais favorecerem o desenvolvimento do patógeno, que pode causar morte das plantas mais jovens e, no caso de Eucalyptus, também a ocorrência de manchas foliares (ScHULTZ, 2011; SCHULTZ et. al., 2015). Atualmente, além das espécies florestais, diversas espécies de plantas ornamentais têm sido infectadas. Por este motivo, a importância de Cylindrocladium spp. tem aumentado ainda mais. Segundo dados de literatura, o gênero Cylindrocladium agrupa 33 espécies (AlfENAS, 1986; Crous et al., 1994; Peerally, 1991). Este fungo é nativo do Brasil e sobrevive saprofiticamente por meio de escleródios no solo e se dissemina no campo por meio de respingos de chuva com solo contendo inóculo, para folhas e ramos do terço inferior da copa das árvores (FERREIRA, 1989; AlfEnAs et al., 2009).

Observa-se, portanto, a necessidade de estudos relacionados a Cylindrocladium spp., patógeno que ganha importância devido à ampliação dos prejuízos econômicos que vem causando, como resultado da diversidade de hospedeiros que pode infectar. Assim, foi propósito deste trabalho verificar o comportamento patogênico de 14 (quatorze) isolados por meio de inoculações em solo e parte aérea em eucalipto e verificar o crescimento em meio sintético Czapeck.

\section{MATERIAIS E MÉTODOS}

Para o estudo foram utilizados os isolados constantes da Tabela 1, todos provenientes de plantas de eucalipto e preservados em água destilada (método de Castellani). A produção dos inóculos ocorreu em meio batataágar-dextrose (BDA), sendo as placas incubadas durante 7 dias à $25^{\circ} \mathrm{C}$, sob fotoperíodo de 12 horas de luz e $12 \mathrm{~h}$ de escuro. Como plantas hospedeiras foram utilizadas mudas de Eucalyptus urophylla e Eucalyptus grandis. Foram realizadas, separadamente, inoculações em solo e na parte aérea. 
Tabela 1 - Isolados do gênero Cylindrocladium utilizados no estudo.

\begin{tabular}{|c|c|}
\hline Número de registro & Espécie \\
\hline MMBF 223 & C. scoparium var. brasiliensis \\
\hline MMBF 238 & C. scoparium \\
\hline MMBF 268 & C. ilicicola \\
\hline MMBF 328 & C. scoparium var. brasiliensis \\
MMBF 421 & C. scoparium \\
MMBF 515 & C.scoparium \\
MMBF $11 / 75$ & C. scoparium \\
MMBF $6 / 78$ & C. scoparium \\
MMBF $12 / 79$ & C. clavatum \\
MMBF $17 / 89$ & C. scoparium \\
MMBF $06 / 03$ & Cylindrocladium sp. \\
MMBF $31 / 04$ & Cylindrocladium sp. \\
MMBF $32 / 04$ & Cylindrocladium sp. \\
MMBF 54/04 & Cylindrocladium sp. \\
\hline
\end{tabular}

Os patógenos foram, separadamente, inoculados em solo esterilizado onde se desenvolviam mudas, aos 20 dias após a emergência, apresentando cerca de 10 $\mathrm{cm}$ de altura e 4 pares de folhas. Para as inoculações uma placa de cada isolado foi, separadamente, homogeneizada em liquidificador com $200 \mathrm{~mL}$ de água destilada. A seguir, uma alíquota $30 \mathrm{~mL}$ da suspensão obtida foi incorporada ao solo de cada vaso contendo uma planta. Ao tratamento controle foi incorporado $30 \mathrm{~mL}$ de uma suspensão resultante da homogeneização de meio BDA com água destilada. Para cada tratamento foram feitas seis (seis) repetições. Todos os tratamentos foram mantidos em casa de vegetação à temperatura ambiente $\left( \pm 27^{\circ} \mathrm{C}\right)$. A avaliação foi realizada pela observação dos sintomas característicos da doença, como necroses na região do colo da plântula, morte, manchas foliares. Com relação às inoculações sobre folhas, a uma placa de cada isolado foram adicionados $10 \mathrm{~mL}$ de água destilada e o micélio friccionado com alça de Drigalsky para liberação dos conídios. A suspensão preparada foi padronizada para a concentração de $10^{5}$ conídios/mL e aspergida sobre ambas as faces das folhas de plântulas de $E$. urophylla e E. grandis, aos 30 dias após a emergência (informar estágio fenológico (numero de folhas/altura). Sobre as folhas das mudas do tratamento controle foi aspergida apenas água destilada. As plântulas foram cobertas com sacos plásticos umedecidos durante 24h. Após esse período a câmara úmida foi removida e todos os tratamentos permaneceram em casa de vegetação, à temperatura ambiente $\left(27^{\circ} \mathrm{C}\right)$. Para 
a avaliação dos resultados foram observados o surgimento ou não dos sintomas característicos da infecção pelo patógeno. Sendo observado resultado positivo, foi realizada a documentação fotográfica e realizado o reisolamento do patógeno para confirmar se os sintomas estavam sendo causados, de fato, pelo microrganismo inoculado. As culturas patogênicas foram reisoladas e cultivadas em meio sintético Czapeck, cujo pH correspondeu a 7,3 $( \pm 0,2)$, conforme informação constante no frasco (empresa Himedia), a qual foi confirmada pela medição realizada em medidor de $\mathrm{pH}$ da marca Alpax. A seguir, as placas foram mantidas em câmara do tipo BOD, a $25^{\circ} \mathrm{C}$, no escuro. As avaliações foram realizadas após 10 (dez) dias de incubação anotando-se o tipo e coloração do micélio. Para cada isolado havia 6 (seis) repetições e, os isolados semelhantes quanto ao tipo do micélio e coloração foram agrupados e os resultados foram documentados fotograficamente.

\section{RESULTADOS E DISCUSSÃO}

Todos os isolados inoculados estavam patogênicos, porém resultando em diferentes sintomas nas plantas de eucalipto, conforme ilustrado pela Figura 1. Os sintomas foram observados a partir de 5 (cinco) dias após as inoculações, sendo caracterizados por lesões na região do colo da planta com coloração escura e que, com o passar do tempo resultam em necrose dos tecidos, tombamento da plântula e a sua morte. No que se refere aos sintomas de parte aérea, foram observadas manchas em folhas, como reação de hipersensibilidade, minúsculas lesões, conforme e/ou necrose agressiva do tecido foliar. A inoculação em solo resultou em lesões no coleto, com posterior murcha e morte das plântulas, que secaram sem tombar. A Figura 1 e a Tabela 1 ilustram os resultados descritos

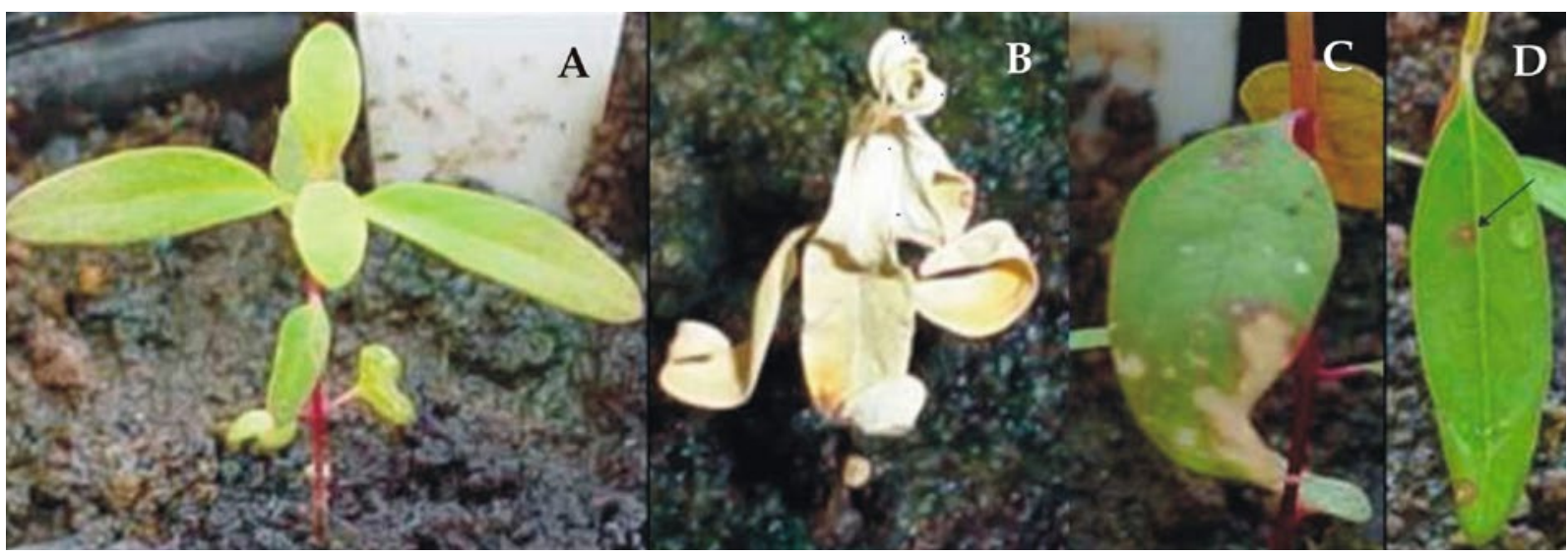

Figura 1 - Sintomas apresentados em diferentes órgãos de Eucalyptus urophylla após as inoculações com isolados de Cylindrocladium. A - Controle; B - Morte causada pela inoculação no solo; C - Mancha e necrose do tecido foliar; D - Reação de Hipersensibilidade (HR - seta). 


\begin{tabular}{|c|c|c|}
\hline Isolado & Solo & Folhas \\
\hline IB223 & + & $+(21$ lesões $)$ \\
\hline IB238 & $\square$ & $+(16$ lesões $)$ \\
\hline IB239 & $\square$ & $+\left(H R^{* *}\right)$ \\
\hline IB268 & $\square$ & + (31 lesões) \\
\hline IB328 & $\square$ & $+\left(H R^{* *}\right)$ \\
\hline IB421 & $\square$ & + (01 lesão) \\
\hline IB515 & $\square$ & $\square$ \\
\hline IB728 & $\square$ & $\square$ \\
\hline IB11/75 & $\square$ & + (33 lesões) \\
\hline IB6/78 & + & $+\left(\mathrm{HR}^{* *}\right)$ \\
\hline IB12/79 & + & $+\left(\mathrm{HR}^{* *}\right)$ \\
\hline IB17/89 & $\square$ & $+\left(\mathrm{HR}^{* *}\right)$ \\
\hline IB01/01 & $\square$ & $+\left(\mathrm{HR}^{* *}\right)$ \\
\hline Cka & $\square$ & $+\left(\mathrm{HR}^{* *}\right)$ \\
\hline FCA06 & + & + (85 lesões) \\
\hline FCA07 & + & + (90 lesões) \\
\hline FCA09 & $\square$ & $+(10$ lesões $)$ \\
\hline FCA10 & $\square$ & + (28 lesões) \\
\hline
\end{tabular}

No que se refere ao crescimento em meio Czapeck, foi possível a formação de 3 (três) grupos: Grupo 1 - Micélio rasteiro (plano) com coloração variando de castanho-rosado pálido a castanho avermelhado intenso; Grupo 2 - Micélio aéreo, com aspecto cotonoso e coloração variando de branco a palidamente róseo; Grupo 3 - Micélio aéreo, com aspecto semi-cotonoso e periferia branca e centro castanho claro. Deve-se ressaltar que isolados pertencentes ao Grupo 1 foram patogênicos às folhas e ao colo de plântulas de E. urophylla, sendo alguns dos mais agressivos (MMBF 06/03, MMBF 31/04 e MMBF 223), uma vez que foram capazes de provocar a morte dos hospedeiros, enquanto que os isolados de outros grupos, causaram prejuízos, como redução no crescimento, mas não a morte da plântula. A Prancha 1 ilustra os resultados descritos. 
Grupo 1

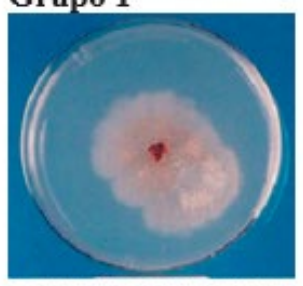

MMBF 54/04

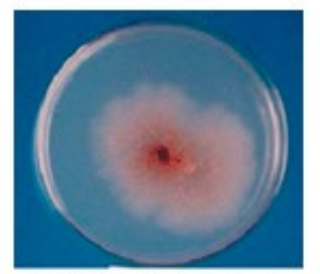

MMBF 06/03

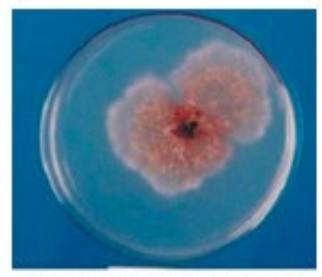

MMBF 17/89

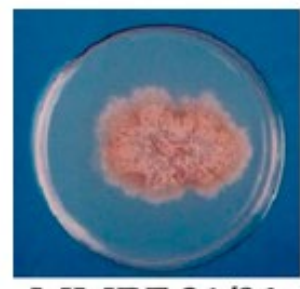

MMBF 31/04

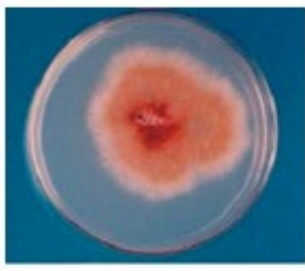

MMBF 12/79

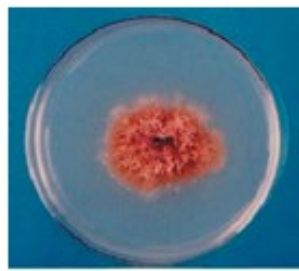

MMBF 06/78

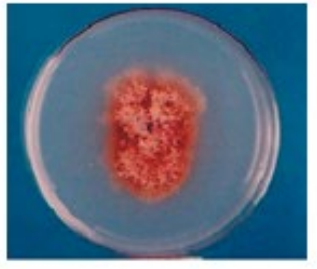

MMBF 223

Grupo 2

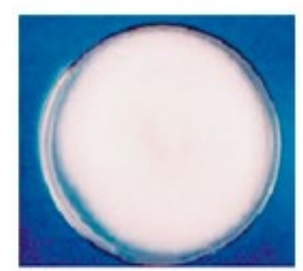

MMBF 421

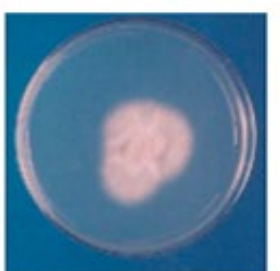

MMBF 328

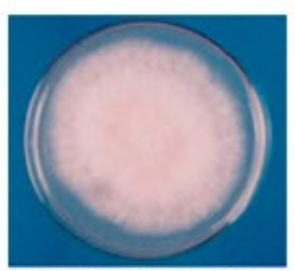

MMBF 11/75

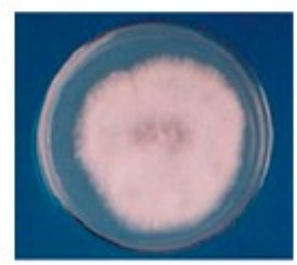

MMBF 32/04

Grupo 3

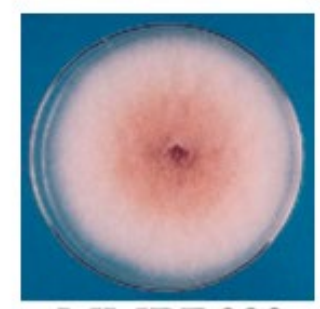

MMBF 238

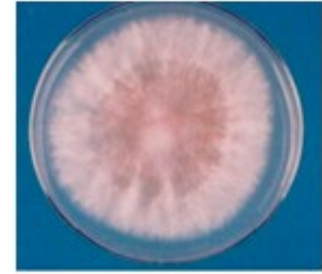

MMBF 268

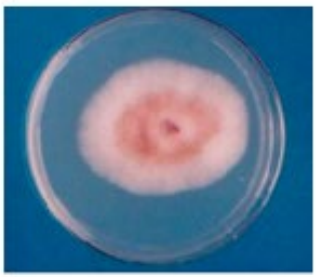

MMBF 515

Prancha 1 - Agrupamento de isolados de Cylindrocladium spp., de acordo com as características de tipo e coloração do micélio e velocidade de crescimento em meio Czapeck.

Segundo RosA; Menezes (2001), a pigmentação e o aspecto da colônia (micélio aéreo ou rasteiro) podem diferir, dependendo do meio de cultura utilizado, de seu pH e da capacidade do isolado em metabolizar componentes do substrato. Neste estudo o pH do meio de cultura correspondeu a 7,3, conforme informação constante no frasco (empresa Himedia), a qual foi confirmada pela medição realizada em medidor de $\mathrm{pH}$ da marca Alpax. Os mesmos autores, estudando alguns isolados de Pseudocercopora musae, observaram crescimento plano do micélio nos meios BDA e V8, com pH 4,5. Nestes mesmos meios, em outros valores de $\mathrm{pH}$, o crescimento do micélio foi aéreo. Com relação à pigmentação, 
para um mesmo isolado, houve variação em função do meio de cultura utilizado (RosA; Menezes, 2001). Griffin (1993) afirmou que esses pigmentos são, em parte, determinados por fatores genéticos e expressos em função do meio ambiente.

JOHNSTON; JONES (1997) também conseguiram separar isolados do gênero Colletotrichum em 16 (dezesseis) grupos distintos com base nas características culturais (cor e aspecto da cultura) desses isolados. Além desses caracteres, a taxa de crescimento da cultura é relatada como possível parâmetro para o agrupamento de isolados (SerRA; Silva, 2004). O meio Czapeck possibilitou a diferenciação dos isolados e, consequentemente, o agrupamento daqueles com características próximas. ORREGo-FUENTE et al. (1996), obtiveram resultados semelhantes também com isolados de Cylindrocladium, porém não só em meio Czapeck, mas também nos meios de coco, soja e cenoura, os quais induziram à variação nas características culturais dos isolados estudados. Em meio BDA isto não foi possível, uma vez que todos os isolados apresentam o mesmo tipo de micélio (cotonoso), coloração de colônia (marromavermelhada intensa) e velocidade de crescimento muito semelhantes. Para $C$. gloeosporioides resultado semelhante em meio BDA foi relatado (SERRA; SILVA, 2004). Devido a não ser um meio de cultura sintético seus constituintes podem apresentar variações, o que pode resultar, para muitos fungos, em uniformidade nas características culturais de diferentes isolados. Ao contrário, os meios sintéticos, como Czapeck, não apresentam variação nas características de seus componentes.

Segundo COCHRANE (1958), fatores nutricionais como micro-elementos essenciais, fontes de carbono e de nitrogênio podem fazer com que os fungos produzam pigmentos e os liberem no meio de cultura. CASTRo; CoElHo (2000), observaram significativa variação no comportamento de Cercospora cruenta no que se refere ao crescimento micelial quando cultivado em diferentes meios de cultura. De acordo com a composição do meio, por exemplo, adição de sais $(\mathrm{KCl}$, $\mathrm{NaCl}, \mathrm{NaNO}_{3}$ ), a morfologia da colônia pode mudar. Os sais podem induzir ao clareamento da colônia uma vez que são nutrientes capazes de interferir na atividade enzimática, metabolismo dos carboidratos, balanço iônico, formação de aminoácidos, nucleotídeos e vitaminas (GRIfFIN, 1993). Porém, não se deve menosprezar a capacidade intrínseca do microrganismo em captar e utilizar os nutrientes do substrato suprindo, assim, suas exigências nutricionais (EKPO; EsURUOSO, 1977; QUEIROZ; MENEZES, 1997). Tal capacidade pode ser devida aos isolados pertencerem a raças fisiológicas distintas, conforme sugerido por AzEVEdo (1997), e serem diferenciados não pela morfologia, mas somente por meio de estudos fisiológicos e moleculares. Vechiato (2002) também conseguiu diferenciar e agrupar 55 (cinquenta e cinco) isolados de 
Diaporthe phaseolorum var. meridionalis observando crescimento e coloração das colônias nos meios Czapeck e BDA. FAgAN (1980), LiYANAGE et al. (1992), Goes; Kimati (1997) e Serra; Silva (2004) conseguiram distinguir "strains" em C. acutatum e C. gloeosporioides, com base na morfologia e crescimento cultural .
Assim, pode-se verificar que o presente estudo possibilitou identificar agrupamentos distintos entre os isolados avaliados, sendo que os semelhantes sob 0 ponto de vista patogênico/ fisiológico permaneceram no mesmo grupo. Foi constatado, também, que o meio Czapeck é bastante adequado no agrupamento de isolados com características semelhantes. 


\section{REFERENNCIAS}

ALFENAS, A.C. Fungos do gênero Cylindrocladium como patógenos florestais no Brasil. Fitopatologia Brasileira, Brasília, v.11, p.275-277, 1986.

ALFENAS, R.F. Produção de inóculo de Cylindrocladium pteridis em condições controladas. 36f. Dissertação (Mestrado em Fitopatologia), Universidade Federal de Viçosa, Viçosa, 2009.

AZEVEDO, J.L. Variabilidade em fungos fitopatogênicos. Summa Phytopathologica, Jaboticabal, v.2, p.3-15, 1997.

CASTRO, N.R.; COÊLHO, R.S.B. Caracterização fisiológica de isolados de Cercospora cruenta em diferentes meios de cultura. Summa Phytopathologica, Jaboticabal, v.26, n.4, p.466-471, 2000.

CROUS, P.W.; WINGFIELD, M.J. A monograph of Cylindrocladium, including anamorphus of Calonectria. Mycotaxon, Portland, v.51, p.341-435, 1994.

EKPO, E.J.A.; ESURUOSO, O.F. Factors affecting spore germination in cowpea isolate of Cercospora_cruenta Sacc. Phytopathology, St. Paul, v.67, p.249-255, 1977.

FAGAN, H.J. Straisn of Colletotrichum gloeosporioides in citrus in Belize. Transactions of the British Mycology Society, London, v.74, n.3, p.643-644, 1980.

GOES, A. de; KIMATI, H. Caracterização patogênica de isolados de Colletotrichum_acutatum e C. gloeosporioides obtidos de plantas cítricas. Summa Phytopathologica, Jaboticabal, v.23, n.1, p.10-14, 1997.

GRIFFIN, D.H. Fungal physiology. New York: Jonh Wiley, 1993. 458p. v.2.

JOHNSTON, P.R.; JONES, D. Relationships among Colletotrichum isolates from fruit-rots assessed using rDNA sequences. Mycologia, Albuquerque, v.89, p.420-430, 1997.

LIYANAGE, H.D.; MCMILLIAN, R.T.; KISTLER, H.C. Two genetically distinct populations of Colletotrichum gloeosporioides fom citrus. Phytopathology, St. Paul, v.82, n.11, p.1371-1376, 1992.

ORREgo FUENTE, A.L.; MENEZES, M.; OLIVEIRA, S.M.A.; COELHO, R.S.B. Análise comparativa de caracteres patogênicos e físico-morfológicos para identificação de espécies de Cylindrocladium. Summa Phytopahologica, Jaboticabal, v.22, p.127-133, 1996.

PEERALLY, A. The classification and phytopathology of Cylindrocladium species. Mycotaxon, Portland, v.40, p.323-366, 1991.

QUEIROZ, F.M.; MENEZES, M. Efeito de meios de cultura e de regimes de luz no crescimento micelial e esporulação de Cercospora cruenta, agente causal da mancha necrótica do caupi. Revista Omega, Recife, v.10, p.36-38, 1997.

ROSA, R.T.C.; MENEZES, M. Caracterização patogênica, fisiológica e morfológica de Peudocercospora musae. Fitopatologia Brasileira, Brasília, v.26, n.2, p.141-147, 2001.

SCHULTZ, B. Doenças bióticas e abióticas em Eucalyptus benthamii Maiden. 2011. 101f. Dissertação (Mestrado) - Universidade Federal do Paraná, Curitiba, 2011.

SCHULTZ, B.; SBRAVATTI JUNIOR, J.A.; AUER, C.G.; SANTOS, A.F. Impacto da mancha foliar causada por Cylindrocladium candelabrum em plantios jovens de Eucalyptus benthamii em Rio Negrinho - SC. Ciência Florestal, Santa Maria, v.25, n.2, p.307-316, 2015.

SERRA, I.M.R. de; SILVA. G.S. da Caracterização morfofisiológica de isolados de Colletotrichum gloeosporioides agentes de antracnose em frutíferas no Maranhão. Summa Phytopahologica, Botucatu, v.30, n.4, p.475-480, 2004.

VECHIATO, M.H. Detecção e identificação de Diaporthe phaseolorum var. meridionalis em sementes de soja por PCR. 2002. 115f. Tese (doutorado) - Universidade Estadual Paulista, Faculdade de Ciências Agronômicas, 2002. Disponível em: <http://hdl.handle.net/11449/105438>. Acesso em: 07 jun. 2019. 